\title{
Physicochemical characterization and calorific value measurement in residual oils used in the petrochemical industry of Cartagena de indias (Colombia)
}

\author{
Waldyr Fong-Silva $^{\# 1}$, Carlos Severiche-Sierra ${ }^{\# 2}$, Eduardo Espinosa-Fuentes ${ }^{* 3}$, Yesid Marrugo- \\ Ligardo $^{\# 4}$, Jose Jaimes-Morales ${ }^{\# 5}$ \\ \# Universidad de Cartagena, Cartagena de indias, Bolivar, Colombia. \\ 1wfongs@unicartagena.edu.co \\ 2cseveriches@gmail.com \\ 4ymarrugol@unicartagena.edu.co \\ 5jjaimesm@unicartagena.edu.co \\ *Corporación Universidad de la Costa, Barranquilla, Atlántico, Colombia. \\ 3eduardo.espinosa.fuentes@gmail.com
}

\begin{abstract}
Residual oils from combustion engines, from the industrial sector of Mamonal in Cartagena de Indias, were characterized by densimetry, karl fischer, viscosimetry, atomic absorption and pump density, percentage of humidity, viscosity, metals in suspension and calorific value Designed, constructed and tuned according to ASTM D 240-02. The calorimetric pump was designed in stainless steel 304 schedule 40, with circular section and internal volume of 355,71 $\mathrm{mL}$. It works in an atmosphere of oxygen with pressures between 25 and 30 atm. The temperature sensor used was the SEE TMP-BTA with stainless steel probe and the data-software acquisition system used was VERNIER International's GOLink SEE with a sensitivity to the hundredth degree. It was determined that the higher calorific value (PCS) of the samples of used oils from the industrial sector of Mamonal have an average value of 19934.3 Btu / Lb.
\end{abstract}

Keyword - Calorimetric pump, Heat power, Oil reused, Physicochemical variables, Recycling.

\section{INTRODUCTION}

The demand for treated oils to be used as an energy source would depend on the cost of the cleaned or cleaned oils, the cost of the fuels to be used if mixed and the behavior of the consumers of the new fuel $[1,2,3]$. The treatments applied to the used oils allow, through a degree of cleaning, to increase the percentage of the lubricant base present in the original oil, so that they are suitable for formulation and use [4,5]. That is, the raw material will be reused, thus achieving the minimum amount of waste discharged into the medium in liquid form $[6,7]$.

Interest as regards used oils, which in most cases have a considerable energy content, are listed as follows [8]:

- Engine oils (Automotive, aircraft, ships, heavy machinery, locomotives, trucks among others)

- Synthetic oils

- Compressor oils

- Di Dielectric oils

- Hydraulic oils

- Cooling Oils

- Oils for thermal insulation

The study of urban solid waste (RSU) and toxic and hazardous waste (RTYP) as used oils has been highly controversial worldwide due to the large amount of dioxins, PCBs and carcinogenic compounds that they generate during their combustion [9]. A number of studies have been carried out in Europe, the United States and Latin America to identify energy contents of this type of substances in order to propose productive recovery and recycling projects [10].

As a worldwide problem, there are currently 400 refining plants used in Europe with a reprocessing capacity of $1800 \mathrm{Kt} /$ year, which are in most cases in Asia and smaller Proportion in Spain, France, Italy and Germany. The above, commits companies, institutions and especially universities to be involved in order to offer strategies to generate projects to recover or reuse toxic waste and especially used oils [11,12]. 
In the first phase of the project a physical-chemical characterization of the samples of used oils was made and in the second phase a study of the calorific power identifying the possibility of developing projects that allow the reutilization of its energy capacity in productive or manufacturing processes, where Can participate as fuel supplying the internal energy they still own.

To develop the second phase, a calorimetric pump was built in stainless steel which works in an oxygen atmosphere and was used to quantify the calorific value of samples of used motor oils from the industrial sector of Mamonal de Cartagena de Indias.

\section{EXPERIMENTAL}

\section{Population and sample}

The population on which was worked the used oils constituted from the industrial sector of Mamonal in Cartagena de indias, as follows:

to. Mobil oil $15 \mathrm{~W} 40$ (engine)

B. Oil Shell Rimula 50 (engine)

C. Shell Oil Omala 220 (hydraulic)

D. Oil SAE 50 Brand Bracol (recovered)

and. Oil SAE 50 Engine Oil Brand (salvaged)

F. Havoline oil $20 \mathrm{~W} 50$ (engine)

G. Fuel Oil

H. Used oil mixed product of used oils of various types.

Samples \# 1 and 2 correspond to used oils obtained from a twin-plate dump TUQ 017 and a motor reducer from Gyplac S.A. Samples \# 3 and 4 are recycled (reclaimed) used motor oils and are found in street vending. Sample \# 5 corresponds to Heavy Oil Fuel Oil, supplied by Suction and Cargo, authorized for the handling of this type of substances classified as toxic and dangerous by national law. Samples \# 6 corresponds to a sample of used oil from a forklift motor of reference type yale S34 of the company Servimac, which corresponds to a motor oils Rimula 50 Shell with 280 hours of work.

\section{Calorimetric Pump Calibration}

Calibration of the calorimetric pump was done according to the procedure described in the ASTM D240-02 subsection 8.1, which consists of averaging four (4) tests using the International standard benzoic acid and three (3) with succinic acid [3] Which were spaced over a period of not less than three days. The tests were done with an oxygen pressure of 200 Psia (1379 kpa or $1.5 \mathrm{~atm}$ ) because there was no pressure regulator of 441 Psia (3040.7 Kpa or $30 \mathrm{~atm}$ ) as specified in the standard. The error of the calorimetric pump built is. The equivalent of the apparatus yielded a value of: $\mathrm{W}=2626.2 \mathrm{Cal} /{ }^{\circ} \mathrm{C}$.

\section{Calibration of temperature sensor}

The calibration of the temperature sensor was done in the metrology laboratory of the company Promigas S.A. of the city of Barranquilla, which is endorsed by the superintendence of industry and commerce of Bogota. The calibration procedure of the temperature sensor consisted of making several sweeps up and down the working range of the sensor, ie between 20 and $40{ }^{\circ} \mathrm{C}$. The process consisted in comparing the measurements of the TMP-BTA vernier sensor with the temperatures sensed by the thermometer proprietary standard of the company promotes, which was previously calibrated in the superintendence of industry and commerce.

The characteristics of the VER-TMP-BTA temperature sensor are as follows:

- Thermistor type sensor NTC $20 \mathrm{k} \Omega$

- Temperature range: $-40^{\circ} \mathrm{C}-135^{\circ} \mathrm{C}$

- Resolution: $0,02^{\circ} \mathrm{C}$ between $0^{\circ} \mathrm{C}$ and $40^{\circ} \mathrm{C}$

- Accuracy: $0,2^{\circ} \mathrm{C}$ a $0^{\circ} \mathrm{C}$ and $0,5^{\circ} \mathrm{C}-100^{\circ} \mathrm{C}$

- Response time: 10 s in water.

- Probe length: $105 \mathrm{~mm}$ and diameter of $4 \mathrm{~mm}$

\section{Physicochemical analysis}

The physicochemical analysis of the oil samples was made by atomic absorption spectroscopy with the Thermo Scientific iCE 3000 equipment for the determination of metals, sediments and ash [13]. To determine the viscosity of the samples, viscosimetry was used, the Karl Fischer method and densimetry were used for the determination of moisture [14]. 


\section{Measurement of calorific value}

The calorific value was measured using the Calorimetric Pump designed and constructed of dimensions 3 inches in diameter by 3 inches in height and which was designed and manufactured taking into account the criteria of ASTM D240-02 [15].

\section{RESUlTS AND DisCuSSION}

The physicochemical analysis performed on the samples of used oils used is then detailed in Tables 1 and 2.

TABLE I. Physicochemical analysis of samples of oils \# 1, 2 and 3

\begin{tabular}{|c|c|c|c|}
\hline Settings & M \#1 & M\#2 & $\mathbf{M \# 3}$ \\
\hline Sample & TUQ.017 & GYPLAC & Retained Oil \\
\hline Application of the machine & Double overhead camshaft & Gearmotor & Motor \\
\hline Oil Mark & Mobil MX 15W40 & Shell Omala 220 & Bracol SAE50 SE/CC \\
\hline Viscosity at $40^{\circ} \mathrm{C}$, cSt & 24,80 & 55,30 & 60,00 \\
\hline Humidity \% & 2,44 & 0,27 & 0,01 \\
\hline Sulfur,\% & 0,85 & 1,14 & 0,16 \\
\hline Aluminum, ppm & 140,74 & 16,41 & 12,28 \\
\hline Iron, ppm & 55,11 & 1521,42 & 3,03 \\
\hline Sodium, ppm & 22,31 & 145,85 & 15,52 \\
\hline Zinc, ppm & 937,28 & 104,32 & 7,04 \\
\hline Copper, ppm & 7,96 & 5,37 & $<0,041$ \\
\hline Tin, ppm & $<0,43$ & $<0,43$ & $<0,43$ \\
\hline Lead, ppm & $<0,10$ & $<0,10$ & $<0,10$ \\
\hline Chromium, ppm & $<0,05$ & $<0,05$ & $<0,05$ \\
\hline Silver, ppm & $<0,034$ & $<0,034$ & $<0,034$ \\
\hline Silicon, ppm & 28,43 & 16,28 & 2,43 \\
\hline Cadmium, ppm & $<0,032$ & $<0,032$ & $<0,032$ \\
\hline Phosphorus, ppm & 10,58 & 24,89 & 5,46 \\
\hline Chlorine, ppm & 24,43 & 224,11 & 18,95 \\
\hline Calcium, ppm & 251,33 & 1064,00 & 48,33 \\
\hline Sediments, \% & 1,57 & 0,44 & $<0,01$ \\
\hline Ashes,\% & 0,98 & 0,22 & 0,0081 \\
\hline Density, Kg / L & 0,8994 & 0,8659 & 0,9004 \\
\hline
\end{tabular}


TABLE II. Physicochemical analysis of samples of oils \# 4, 5 and 6

\begin{tabular}{|l|c|c|c|}
\hline \multicolumn{1}{|c|}{ Settings } & M\#4 & M\#5 & M\#6 \\
\hline \multicolumn{1}{|c|}{ Sample } & Retained Oil & Succión y Carga & Servimac S.A. \\
\hline Application of the machine & Motor & Motor Marine & Forklift \\
\hline \multicolumn{1}{|c|}{ Oil Mark } & Motor Oil SAE 50 & Fuel Oil No.4 & Shell Rimula 50 \\
\hline Viscosity at 40 ${ }^{\circ} \mathrm{C}$, cSt & 50,85 & 72,28 & 56,80 \\
\hline Humidity \% & 0,0094 & 0,447 & 1,48 \\
\hline Sulfur,\% & 0,12 & 0,65 & 1,21 \\
\hline Aluminum, ppm & 11,41 & 13,54 & 11,20 \\
\hline Iron, ppm & 4,89 & 227,86 & 148,80 \\
\hline Sodium, ppm & 13,48 & 492,07 & 410,07 \\
\hline Zinc, ppm & 6,37 & 17,93 & 901,51 \\
\hline Copper, ppm & $<0,041$ & 10,38 & 17,40 \\
\hline Tin, ppm & $<0,43$ & $<0,43$ & $<0,43$ \\
\hline Lead, ppm & $<0,10$ & $<0,10$ & $<0,10$ \\
\hline Chromium, ppm & $<0,05$ & $<0,05$ & $<0,05$ \\
\hline Silver, ppm & $<0,034$ & $<0,034$ & $<0,034$ \\
\hline Silicon, ppm & 5,20 & 49,69 & 6,21 \\
\hline Cadmium, ppm & $<0,032$ & $<0,032$ & $<0,032$ \\
\hline Phosphorus, ppm & 4,97 & 24,17 & 19,79 \\
\hline Chlorine, ppm & 15,80 & 709,45 & 635,00 \\
\hline Calcium, ppm & 41,28 & 171,80 & 401,48 \\
\hline Sediments,\% & $<0,01$ & 0,05 & 0,18 \\
\hline Ashes,\% & 0,0079 & 0,186 & 0,932 \\
\hline Density, kg / L & 0,9010 & 0,8663 & 0,99786 \\
\hline
\end{tabular}

The deterioration of the used motor oils used in the industrial sector of Mamonal is mainly due to several factors, among which the following stand out: The presence of calcium, magnesium, sodium, zinc, phosphorus are the product of the additives used to improve The physical-chemical properties of the oils. Just as the presence of iron in the samples represents wear on the cylinders, shirts, piston rings, valve train and rust. The chrome is due to the wear of the piston rings and the refrigerants used. The existence of aluminum is due to the wear of the engine pistons. The presence of copper is due to the wear of bearings, bushings and coolant additives. The reduction of the viscosity of the oil is due to the dilution by filtration of fuel. The presence of silicon is due to the filtration of dust and abrasive particles through the inefficient air filters. The presence of ash and sediment (insoluble) is due to poor combustion and the excessive interval between oil changes. The content of lead, chromium, silver and cadmium in the analyzed samples is less than $0.1 \mathrm{ppm}$, which would allow a possible energy utilization for this type of oils.

We present below a calculation of the upper calorific value for the oil sample No.1. The other calculations were done in the same way.

Sample No.1:

$$
P C S=\frac{2626,2 *(5+0,0624)-4,13-4,875}{1,1315}
$$

Temperatures in main test

Temperature Minor: $29.91^{\circ} \mathrm{C}$ (at 5 minutes) Correction: -0.735.

High Temperature: $34.88^{\circ} \mathrm{C}$ (at 10 minutes) Corrected: - 0.695

Temperature Minor corrected: $29.175^{\circ} \mathrm{C}$

High Temperature Corrected: $34.047^{\circ} \mathrm{C}$

$\Delta \mathrm{T}=34,185-29,175=5,01 \cong 5^{\circ} \mathrm{C}$

$\mathrm{C}=0,0624^{\circ} \mathrm{C}$

$e_{1}=4,13 \mathrm{Cal}$

$e_{2}=(0,0283-0,0154) * 377,893=4,8748 \mathrm{Cal}$

$\mathrm{M}=1,1315 \mathrm{~g}$ 


$$
\begin{aligned}
& \text { PCS }=11741,82 \pm 11,3 \% \frac{C a l}{g}=49151,26 \pm 11,3 \% \frac{J}{g}= \\
& =49,151 \pm 11,3 \% \frac{M J}{K g}=21131,24 \pm 11,3 \% \frac{B t u}{L b}
\end{aligned}
$$

After completing the calculations, we compared the calorific powers of the samples \# 2, 3 and 4 determined in the laboratory of fuel combustion of the University of the Valley with the results of the same samples obtained with the calorimetric pump designed and constructed. In Tables 3, 4 and 5 we can observe the PCS (High Calorific Power) and the mean value obtained for the used oil samples \# 2,3 and 4 analyzed.

TABLE III. High Calorific Power of samples of used oils analyzed in the combustion laboratory of fuels of the Universidad del Valle

\begin{tabular}{|l|c|c|}
\hline Used Oil Samples & $\begin{array}{c}\text { High Calorific Power (Btu/Lb) } \\
\text { UniValle }\end{array}$ & $\begin{array}{c}\text { Average Calorific Value } \\
\text { UniValle }\end{array}$ \\
\hline Sample \#2 & 19552 & \multirow{2}{*}{19555,33} \\
\hline Sample \#3 & 19577 & \\
\hline Sample \#4 & 19537 & \\
\hline
\end{tabular}

TABLE IV. Superior Calorific Power of samples of used oils analyzed at the University de Cartagena, with the calorimetric pump designed and built

\begin{tabular}{|l|c|c|}
\hline \multicolumn{1}{|c|}{ Used Oil Samples } & $\begin{array}{c}\text { High Calorific Power (Btu/Lb) } \\
\text { UniCartagena }\end{array}$ & $\begin{array}{c}\text { Average Calorific Value } \\
\text { UniCartagena }\end{array}$ \\
\cline { 1 - 2 } Sample \#2 & $20723,95 \pm 11,3 \%$ & \multirow{2}{*}{$21188,03 \pm 11,3 \%$} \\
\cline { 1 - 2 } Sample \#3 & $21780,22 \pm 11,3 \%$ & \\
\cline { 1 - 2 } Samp & $21059,92 \pm 11,3 \%$ & \\
\hline
\end{tabular}

Then, in Table 5, we can see the deviation, percentage of error and average error of the equipment constructed with respect to the values obtained in the laboratory of fuel combustion of the University of the valley for samples \# 2, 3 and 4.

TABLE V. Deviation, error percentage and mean error of the samples \# 2, 3 and 4 analyzed in the Universidad de Cartagena with the equipment constructed, with respect to the same samples analyzed in the laboratory of combustion of fuels of the Universidad del Valle

\begin{tabular}{|c|c|c|c|}
\hline $\begin{array}{c}\text { Used Oil } \\
\text { Samples }\end{array}$ & $\begin{array}{c}\text { Deviation from } \\
\text { UniValle }\end{array}$ & $\begin{array}{c}\text { Percentage of error with } \\
\text { respect to UniValle (\%) }\end{array}$ & $\begin{array}{c}\text { Average error with } \\
\text { respect to UniValle }\end{array}$ \\
\cline { 1 - 3 } Sample \#2 & $-1169,86$ & $-5,98$ & \multirow{2}{*}{$-3,90 \mathrm{z}$} \\
\cline { 1 - 3 } Sample \#3 & $-257,94$ & $-1,32$ & \\
\hline Sample \#4 & $-856,85$ & $-4,39$ & \\
\hline
\end{tabular}

To calculate the deviation of the PCS with respect to the one determined by the University of the Valley, proceed as follows: For sample \# 2 (Table 4): 18382,14 this value is below the value calculated by the Universidad del Valle in (Table 5): $-1169,86$ and that appears in the previous table. In the same way we proceeded for the other values. The error rate is calculated for this value as follows:

$$
\% E=\frac{-1169,86 \% * 100}{19552}=-5,98 \% \quad \text { (3), by default }
$$

According to the average error calculated in Table 5, we can assure that our equipment meets the quality specifications necessary to determine not only calorific powers of new and used oils in general but of any type of substance, compound or solid, since its precision Reaches the 96,1\%.

According to the previous results, the low content of used oils of elements such as lead, cadmium and chromium irritants of the airways and carcinogens, allows to suggest a possible use as alternative fuel for this type of oils. This alternative constitutes an option that allows re-introducing to the production chain to this type of substances cataloged as toxic and dangerous by national law.

\section{CONCLUSION}

From the results shown, from its analysis and discussion, we can obtain the following conclusions about the physicochemical characterization and measurement of the calorific value of residual oils from the petrochemical industry of Cartagena de indias: 1) Insoluble materials present in the oil Are a product of dust, soot, poor combustion, low compression ratio, problems with injectors or spark plugs, inefficient air filters and excessive time interval between oil changes; 2) The presence of metals in used oils is mainly due to the action of acids 
acting on the parts and components of the engine through which it circulates, causing the decomposition of the same; 3 ) The use of the used oil as an alternative fuel is valid if the physical-chemical treatments necessary to declassify it as a toxic and hazardous waste are carried out; and 4) The designed and built calorimeter pump complies with ASTM D 240-02, has an ignition system, external adiabatic system, data-interface-software system with all its accessories and determines the power Higher calorific value of samples of used oils with a precision level of $\pm 11.3 \%$.

\section{REFERENCES}

[1] S. Anouti, G. Haarlemmer, M. Déniel, and A. Roubaud. "Analysis of Physicochemical Properties of Bio-Oil from Hydrothermal Liquefaction of Blackcurrant Pomace,” Energy Fuels., vol. 30, no.1, pp. 398-406, 2016.

[2] C. Severiche, R. Acevedo and J. Jaimes, "Landfill Mining As a Management Alternative for Solid Waste,” Producción Mas Limpia., vol. 9, no.1, pp. 115-123, 2014.

[3] C. Severiche and R. Acevedo “ Biogas from Organic Waste and its Bet as Second Generation Fuels,” Ingenium., vol. 14, no. 28, pp. 6 $-15,2013$.

[4] C. Ewulonu, and I. Igwe, "Properties of Oil Palm Empty Fruit Bunch Fibre Filled High Density Polyethylene," International Journal of Engineering and Technology., vol.3, no. 6, pp. 458-471, 2011-2012.

[5] W. Fong, L. Vargas, C. Severiche, E. Espinosa and Y. Marrugo, "Multivariate analysis on the influence of physicochemical parameters on the calorific value of oils used in the petrochemical industry," International Journal of Engineering and Technology., vol. 9, no. 4, pp. 3355-3360, 2017.

[6] K. Sarker, "Review and Comparison of Various Properties of Jatropha oil Biodiesel," International Journal of Engineering and Technology., vol. 7, no .6, pp.1965-1971, 2015-2016.

[7] E. Espinosa, J. Castro, D. Meza, L. Pacheco and S. Hernández, "Sublimation enthalpy of homemade peroxide explosives using a theoretically supported non-linear equation,” Journal of Thermal Analysis and Calorimetry., vol. 19, no. 1, pp. 681-688, 2015.

[8] M. Das-Ghatak and P. Mahanta, "Biogas Purification using Chemical Absorption," International Journal of Engineering and Technology., vol. 8, no. 3, 1600-1605, 2016.

[9] E. Bedoya, C. Severiche, D. Sierra and M. Meza, "Diagnosis of solid waste management in the petrochemical-plastic sector of Cartagena de indias, Northern Colombia,” International Journal of Engineering and Applied Sciences., vol. 4, no. 6, pp. 37 - $39,2017$.

[10] K. Tyagi, and M. Khan, "Effect of Gas Turbine Exhaust Temperature, Stack Temperature and Ambient Temperature on Overall Efficiency of Combine Cycle Power Plant,” International Journal of Engineering and Technology., vol. 2, no. 6, 427-429, 2010.

[11] P. Doshi, G. Srivastava, G. Pathak and M. Dikshit, "Physicochemical and thermal characterization of nonedible oilseed residual waste as sustainable solid biofuel,” Waste Management., vol. 34, no. 10, 1836-1846, 2014.

[12] J. Gandure, C. Ketlogetswe and A. Temu, "Fuel properties of biodiesel produced from selected plant kernel oils indigenous to Botswana: A comparative analysis,” Renewable Energy, vol. 68, pp. 414-420, 2014.

[13] L. Vlaev, P. Petkov, A. Dimitrov and S. Genieva, "Cleanup of water polluted with crude oil or diesel fuel using rice husks ash," Journal of the Taiwan Institute of Chemical Engineers., vol. 42, no. 6, 957-964, 2011.

[14] E. Espinosa, A. Pájaro, F. Colpas and E. Meza, "Nonlinear models of the experimental thermal profile," Journal of Thermal Analysis and Calorimetry., vol. 123, no. 1, pp. 813-818, 2016.

[15] J. Hu, J. Gan, J. Li, Y. Luo, G. Wang, L. Wu and Y. Gong, "Extraction of crude oil from petrochemical sludge: Characterization of products using thermogravimetric analysis," Fuel., vol. 188, pp. 166-172, 2017.

\section{AUTHOR PROFILE}

${ }^{1}$ Waldyr Fong-Silva. Mechanical Engineer at Bolivar University, University Teaching Specialist at Magdalena University, Master's Degree in Education at the University of Seville, Master's Degree in Physical Sciences at the University of Cartagena and Doctorate in Sciences at the Dr. Rafael Belloso Chacin University. He is currently Director of the Metrology Program of the University of Cartagena and leader of the Research Group GIMIFEC of the same university.

${ }^{2}$ Carlos Severiche-Sierra. He received the title of Chemist from the University of Cartagena, a title of Specialist in Sanitary and Environmental Engineering by the University of Cartagena, the degree of Magister in Sustainable Development and Environment by the University of Manizales, degree Specialist in Health and Safety at Work from the Autonomous University of the Caribbean, he is currently a Doctor of Science candidate at the Dr. Rafael Belloso Chacin University. He is currently a research professor at the University of Cartagena and Comfenalco Technological University Foundation.

${ }^{3}$ Eduardo Espinosa-Fuentes. He received his degree in Chemistry in 2004 from the University of Cartagena, a Master's degree in Chemistry from the University of Puerto Rico (2010) and a Doctor of Chemistry from the University of Puerto Rico (2014). He is currently a research professor at the Corporación Universidad de la Costa.

${ }^{4}$ Yesid Marrugo-Ligardo. Bachelor in Biology and Chemistry, Food Engineer, Food Science and Technology Specialist, Master in Food Science and Technology, he is currently a Doctor of Science candidate at the Dr. Rafael Belloso Chacin University. He is currently a research professor at the University of Cartagena. Leader of the Research Group on Environment, Food and Health MAAS.

${ }^{5}$ Jose Jaimes-Morales. Bachelor in Biology and Chemistry, Food Engineer, Food Science and Technology Specialist, Master in Food Science and Technology, Master in chemical engineering, Masters in biochemistry. He is currently a Doctor of Science candidate at the Dr. Rafael Belloso Chacin University. He is currently a research professor at the University of Cartagena. 